\title{
Local and Distributed Effects of Apomorphine on Fronto-Temporal Function in Acute Unmedicated Schizophrenia
}

\author{
Paul C. Fletcher, ${ }^{1,3}$ Christopher D. Frith, ${ }^{1}$ Paul M. Grasby, ${ }^{2}$ Karl J. Friston, ${ }^{1}$ and Raymond J. Dolan ${ }^{1,3}$ \\ ${ }^{1}$ Wellcome Department of Cognitive Neurology, Institute of Neurology, London WC1N 3BG, United Kingdom, ${ }^{2}$ MRC \\ Cyclotron Unit, Hammersmith Hospital, London W12, United Kingdom, and ${ }^{3}$ Royal Free Hospital School of Medicine, \\ London NW3, United Kingdom
}

\begin{abstract}
We used positron emission tomography (PET) to measure brain activity in healthy control subjects and unmedicated patients with schizophrenia. Subjects were scanned in the context of a combined psychological and pharmacological challenge, and we examined the effects of apomorphine, a drug acting on dopamine receptors, on brain systems engaged by a paced verbal fluency task. This factorial design enabled comparison of control subjects and schizophrenics in terms of the activations engendered by the cognitive task and the pharmacological challenge and the interaction of the two. We report a failure of cognitive task-related activation in anterior cingulate cortex and of task-related deactivation in the left superior temporal gyrus in the schizophrenic subjects. Compared with controls, the
\end{abstract}

impaired cingulate activation was significantly reversed by apomorphine. Additionally, there was a trend for the abnormal fronto-temporal pattern of activation in schizophrenic subjects to be normalized by the drug. Overall, in schizophrenic subjects the effect of apomorphine, which we interpret in terms of a net dopaminergic antagonism, was to modify the brain activity, making the pattern more akin to that seen in control subjects. The results indicate both a regionally specific abnormality of brain function in schizophrenia and an abnormal pattern of fronto-temporal interactions.

Key words: PET; schizophrenia; apomorphine; verbal fluency; fronto-temporal interaction
Schizophrenia is a psychotic illness characterized by an early age of onset, symptoms such as delusions, hallucinations, disordered thinking, and impoverished action and, often, a chronic, deteriorating course (American Psychiatry Association, 1987). The underlying pathophysiology is unknown. A functional abnormality is suggested by a relapsing and remitting course, fluctuations in symptoms, and response to pharmacological interventions. The clinical phenomena in schizophrenia contrast with the circumscribed deficits seen in classical neuropsychological disorders after discrete brain lesions (Frith, 1992). The diversity of symptoms in schizophrenia makes it unlikely that the pathophysiology can be accounted for by localized brain dysfunction. The dynamic nature of the clinical picture is strongly indicative of an abnormality, rather than an absence, of function.

Two general theoretical approaches to understanding higher brain function emphasize functional segregation and functional integration, respectively. In the former, specific cognitive processes or operations are localized to discrete anatomical modules (Phillips et al., 1984). In the latter, cognitive processes are emergent properties of interconnected, although anatomically separate, modules (Tononi et al., 1992). Although there is considerable understanding of segregated function, the processes underlying functional integration are a matter of debate (Engel et al., 1992; Tononi et al., 1994). The majority of neurological research in schizophrenia has been predicated on a segregationist perspective. However, one important historical view of the pathophysiology of the psychoses has emphasized

Received May 23, 1996; revised Aug. 7, 1996; accepted Aug. 9, 1996.

P.C.F., C.D.F., K.J.F., and R.J.D. were supported by grants from the Wellcome Trust. P.M.G. was supported by the Medical Research Council.

Correspondence should be addressed to Paul Charles Fletcher, Wellcome Department of Cognitive Neurology, Institute of Neurology, Queen Square, London WC1N 3BG, UK.

Copyright (C) 1996 Society for Neuroscience $0270-6474 / 96 / 167055-08 \$ 05.00 / 0$ that a disorder of integrative function could provide the mechanistic basis for the observed psychological dysfunction (Wernicke, 1906). A splitting or disintegration of psychological function was emphasized in the earliest phenomenological formulations of schizophrenia, and the concept of a split is, of course, inherent in the name itself (Bleuler, 1987).

Little is known regarding the primary pathophysiology of schizophrenia. However, the suggestion of a dopaminergic abnormality (Randrup and Munkvad, 1972) remains central and is supported by evidence from the psychosis-inducing effects of dopamine agonists (Davidson et al., 1987) and by the antipsychotic effects of dopamine antagonists (Creese et al., 1976; Seeman et al., 1976; Johnstone et al., 1978). Direct evidence for an abnormality in dopamine function has been lacking, and in vivo, quantitative, PET studies of dopamine receptor numbers have been inconclusive (Wong et al., 1986; Farde et al., 1988, 1990). However, functional imaging provides evidence of increased dopamine function in schizophrenic patients (Wong et al., 1986; Hietala et al., 1995) coupled with complementary evidence of increased central dopa decarboxylase activity (Reith et al., 1994; Hietala et al., 1995).

Primate studies suggest that the functional effects of dopamine are most appropriately studied in relation to its regulatory role on cognitive functions mediated by the prefrontal cortex (GoldmanRakic et al., 1992). Human functional imaging has provided parallel evidence for dopamine regulation of prefrontal cortex function (Friston et al., 1991; Grasby et al., 1992a,b). We therefore chose to study dopamine function in schizophrenic patients in the context of a task-related prefrontal activation based on a combined psychological and pharmacological manipulation. Preliminary data from the current experiment, indicating a regional dysfunction in the anterior cingulate cortex and its modulation by 


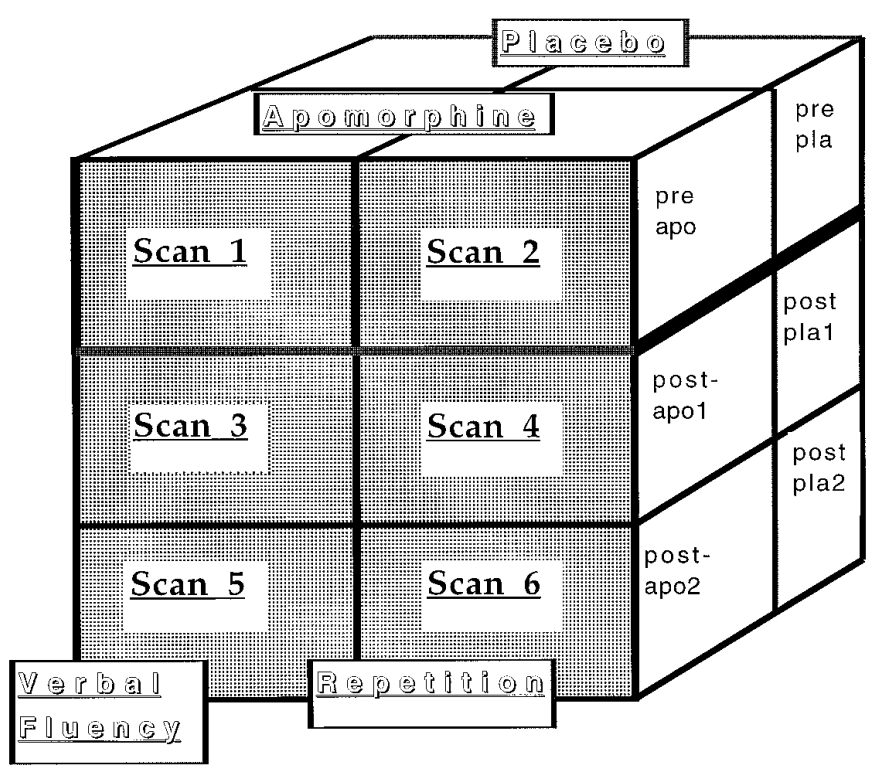

Figure 1. Diagrammatic representation of the study design. Each subject underwent 6 scans. Scans 1, 3, and 5 correspond to the verbal fluency task, whereas Scans 2, 4, and 6 correspond to the control word repetition task. After scan 2, each subject received either apomorphine or placebo. Thus, this constituted a $3 \times 2 \times 3$ split-plot design.

a dopamine perturbation, have been the subject of a previous short report (Dolan et al., 1995). In this report, we provide a more extended account of the findings and present evidence of a disruption of integrative functions in acute unmedicated schizophrenic patients.

\section{MATERIALS AND METHODS}

Twelve right-handed subjects who met DSM-III-R criteria for schizophrenia were recruited from hospitals, outpatient departments, and general practitioners in London. Their mean age was $26 \pm 7$ years, and they had a mean duration of illness (as estimated from personal interview, interviews with relatives, and medical records) of $4.3 \pm 6$ years. All of the patients had been free of neuroleptic medication for at least 6 months and, of the 12, 9 were neuroleptic-naive). Twelve healthy, age-matched control subjects were recruited through advertisement. None had any past history of psychiatric or neurological illness. The study was approved by the local hospital ethics committee and the Administration of Radioactive Substances Advisory Committee (UK; ARSAC).

All subjects underwent six measurements of brain activity over a $1.5 \mathrm{hr}$ period at the MRC Cyclotron Unit, Hammersmith hospital. Scans were obtained using a CTI model 953B PET Scanner (CTI, Knoxville, TN) with collimating septa retracted. Volunteers received a $2 \mathrm{~min}$ intravenous infusion of $\mathrm{H}_{2}{ }^{15} \mathrm{O}$ at a concentration of $55 \mathrm{MBq} / \mathrm{ml}$ and a flow rate of 10 $\mathrm{ml} / \mathrm{min}$ through a forearm cannula. Scans were acquired over a $165 \mathrm{sec}$ period. All measurements were corrected for attenuation by transmission scans.

Psychological tasks. During three of the PET measurements, subjects were required to perform a paced orthographic verbal fluency task. A chosen letter was repeated by the experimenter at a rate of once per $5 \mathrm{sec}$. Subjects were required to produce verbally a word beginning with that letter for each repetition. If a subject was no longer able to produce a response for a given letter, he was instructed to say "pass" and the experimenter switched to a different letter. The control condition, also performed three times, alternating with the experimental condition, was a paced word repetition task at a rate of one item per $5 \mathrm{sec}$ and, therefore, involved the same number and frequency of cues and responses as the verbal fluency task.

Pharmacological challenge. After the second PET scan, six of the subjects from each of the two groups (the schizophrenic and the control groups) were given apomorphine $(10 \mathrm{mg} / \mathrm{kg}$, s.c.). After another $10 \mathrm{~min}$, scanning was resumed and the last four scans were obtained. The other six subjects in each group were given a placebo subcutaneous injection

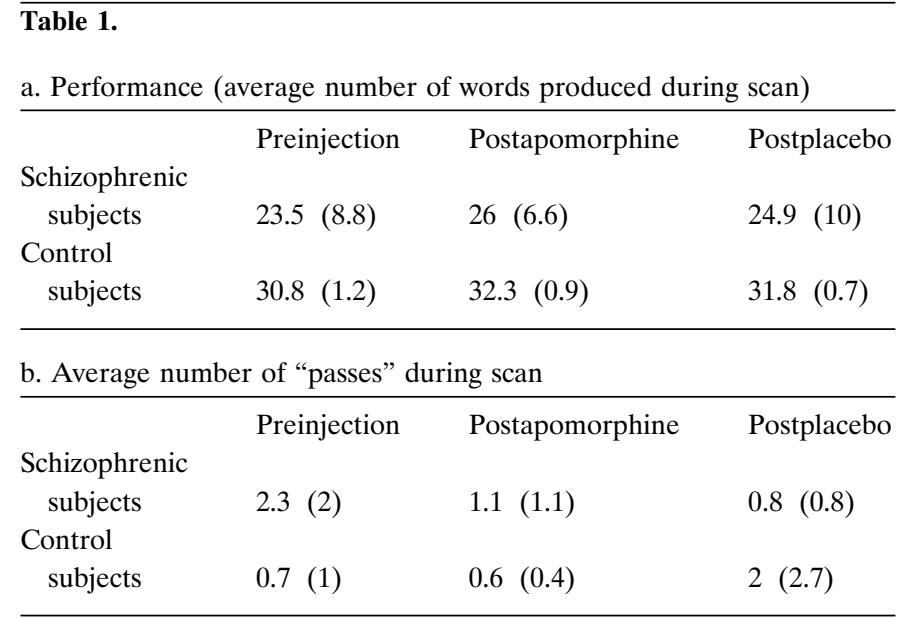

(water) after their second scan. The experimental design is summarized in Figure 1.

Data analysis. The data were analyzed with statistical parametric mapping (using SPM95 software from the Wellcome Department of Cognitive Neurology, London, UK) implemented in Matlab (Mathworks, Sherborn, MA). Statistical parametric mapping combines the general linear model (to create the statistical parametric map or SPM) and the theory of Gaussian fields to make statistical inferences about regional effects (Friston et al., 1995).

In brief, the scans from each subject were realigned using the first scan as reference (Friston et al., 1995). After realignment, all images were transformed into a standard space (Talairach and Tournoux, 1988). This normalizing spatial transformation matches each scan to a reference template image that already conforms to the standard space (Friston et al., 1996). As a final preprocessing step, the images were smoothed using an isotropic Gaussian kernel (FWHM $12 \mathrm{~mm}$ ). The condition, subject, and covariate effects were estimated according to the general linear model at each voxel (Friston et al., 1995). To test hypotheses about regionally specific condition effects, the estimates were compared using linear compounds or contrasts. The resulting set of voxel values for each contrast constitutes a statistical parametric map of the $t$ statistic, SPMt. The SPMt were transformed to the unit normal distribution (SPMZ) and thresholded at $p=0.001$ uncorrected for multiple comparisons.

\section{RESULTS}

\section{Verbal fluency data}

The task was not designed to test the subjects' performance but, rather, to ensure that all subjects were attempting the task throughout the scanning period. Despite pacing, schizophrenic subjects were slightly slower than control subjects, producing fewer responses during the scanning time. However, these differences were nonsignificant. Similarly, schizophrenic subjects tended to produce more "pass" responses, but these differences were also not significant on $t$ testing. Performance within and across groups was not significantly influenced by apomorphine injection. Performance figures are summarized in Table 1.

\section{PET results}

Verbal fluency activations in control and schizophrenic subjects To examine activations associated with the verbal fluency task, we restricted the analysis to the nonapomorphine scans because a cognitive task-associated activation in the presence of apomorphine would incorporate, to some extent, an interaction with the drug. In the control subjects, the verbal fluency task was associated with activation of the following areas: the prefrontal cortex bilaterally, the anterior cingulate cortex, and thalamic/subthalamic regions. These results are presented as an SPM (Fig. 2a) and summarized in Table 2. In the schizophrenic subjects, there 

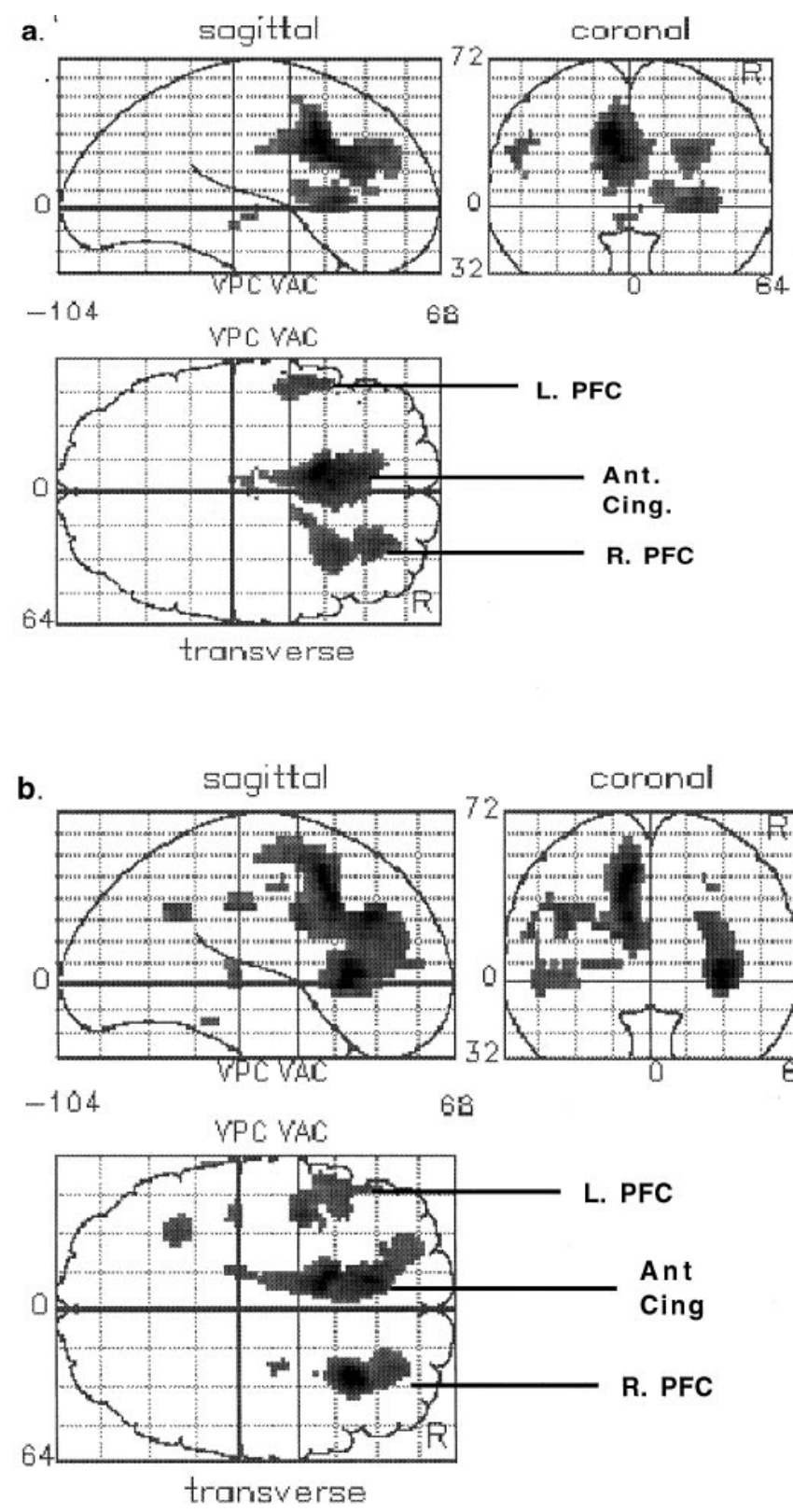

Figure 2. Statistical parametric maps (SPMs) showing brain regions activated in the verbal fluency task relative to the control task. $a$, Control subjects. $b$, Schizophrenic subjects. Areas of significant $(p<0.001)$ activation are shown in black within a representation of a standard brain space (Talairach and Tournoux, 1988). Views are from the right (sagittal), behind (coronal), and above (transverse). Transverse slices are labeled to show the main areas activated (L. PFC and $R$. PFC: left and right prefrontal cortex, respectively; Ant. Cing.: anterior cingulate gyrus).

was also task-associated activation in the prefrontal cortex bilaterally and the anterior cingulate gyrus. In addition, activations were seen in the left inferior parietal lobe, the left superior temporal gyrus, and the posterior cingulate gyrus. These results are summarized in Figure $2 b$ and Table 2.

\section{Verbal fluency deactivations in control and schizophrenic subjects}

Again, the analyses of the cognitive task effects were restricted to nonapomorphine scans to avoid effects resulting from drug interactions. In the control subjects, there were relative decreases in

\begin{tabular}{|c|c|c|}
\hline Region & $\begin{array}{l}\text { Coordinates }{ }^{b} \\
(x, y, z)\end{array}$ & $\begin{array}{l}Z \\
\text { score }\end{array}$ \\
\hline \multicolumn{3}{|l|}{ Control subjects } \\
\hline Left anterior cingulate (BA 24/32) & $\begin{array}{l}-10,12,36 \\
-4,16,24 \\
-12,26,28\end{array}$ & $\begin{array}{l}7.2 \\
6.6 \\
5.8\end{array}$ \\
\hline $\begin{array}{l}\text { Right inferior and medial frontal gyri } \\
\text { (BA 45/46) }\end{array}$ & $\begin{array}{l}30,20,4 \\
26,40,28\end{array}$ & $\begin{array}{l}5.4 \\
5.2\end{array}$ \\
\hline $\begin{array}{l}\text { Left inferior and medial frontal gyri } \\
\text { (BA } 44 / 45 / 46 / 9 \text { ) }\end{array}$ & $\begin{array}{l}-52,4,28 \\
-42,30,32 \\
-48,34,16\end{array}$ & $\begin{array}{l}4.6 \\
3.2 \\
3.1\end{array}$ \\
\hline $\begin{array}{l}\text { Left subthalamic regions } \\
\text { Right subthalamic regions }\end{array}$ & $\begin{array}{l}-4,-18,-4 \\
4,-16,0\end{array}$ & $\begin{array}{l}3.8 \\
3.2\end{array}$ \\
\hline \multicolumn{3}{|l|}{ Schizophrenic subjects } \\
\hline Left anterior cingulate (BA 32) & $\begin{array}{l}-12,10,44 \\
-10,30,28\end{array}$ & $\begin{array}{l}6.5 \\
6.1\end{array}$ \\
\hline $\begin{array}{l}\text { Right inferior and medial frontal gyri } \\
\text { (BA 44/45/46/9) }\end{array}$ & $\begin{array}{l}28,22,4 \\
24,38,24 \\
26,38,16\end{array}$ & $\begin{array}{l}6.7 \\
4.9 \\
4.9\end{array}$ \\
\hline $\begin{array}{l}\text { Left inferior and medial frontal gyri } \\
\text { (BA 44/45/46/9) }\end{array}$ & $\begin{array}{l}-38,0,28 \\
-52,12,20 \\
-48,14,4 \\
-48,14,32\end{array}$ & $\begin{array}{l}5.1 \\
4.4 \\
4.2 \\
3.6\end{array}$ \\
\hline Left inferior parietal lobe (BA 40) & $-32,-56,32$ & 4.3 \\
\hline Posterior cingulate gyrus (BA 23/31) & $-16,-30,32$ & 4.1 \\
\hline Left superior temporal gyrus (BA 22) & $-38,-28,4$ & 4 \\
\hline
\end{tabular}

${ }^{a}$ Scans performed in the presence of apomorphine were excluded.

${ }^{b}$ Talairach and Tournoux, 1988.

$\mathrm{rCBF}$ in the fluency compared to the control condition centered on the superior temporal gyri bilaterally and the posterior cingulate gyrus (Table 3). Likewise, in the same comparison the schizophrenic subjects showed decreases in the superior temporal gyrus bilaterally (far less spatially extensive than those seen in controls with some areas of activation) and in the posterior and midcingu-

\begin{tabular}{lll}
\hline \multicolumn{2}{l}{ Table 3. Relative deactivations in verbal fluency task } & \\
& $\begin{array}{l}\text { Coordinates } \\
\end{array}$ & $\begin{array}{l}Z \\
(x, y, z)\end{array}$ \\
score \\
\hline Region & & \\
\hline Control subjects & $-44,-26,12$ & 6.2 \\
$\quad$ Left superior temporal gyrus & $-48,-14,8$ & 5.8 \\
$\quad$ (BA 22/42) & $-46,-34,16$ & 5 \\
& $50,-12,12$ & 5.3 \\
Right superior temporal gyrus & $46,-20,12$ & 4.9 \\
$\quad$ (BA 22/42) & $2,-52,8$ & 4 \\
Posterior cingulate gyrus (BA 29/30) & & \\
Schizophrenic subjects & $-44,-12,8$ & 4.6 \\
Left superior temporal/inferior parietal & $-50,-28,20$ & 4.2 \\
$\quad$ gyrus (BA 22/40) & $50,-18,8$ & 3.8 \\
Left superior temporal gyrus & $42,-22,8$ & 3.2 \\
$\quad$ BA 22/40) & $6,-52,8$ & 4.9 \\
Posterior cingulate gyrus (BA 29/30) & $2,-10,40$ & 5.3 \\
Cingulate gyrus (MID???) BA 24 & $40,8,44$ & 5.2 \\
Right middle frontal gyrus (BA 6/8) & $-28,-70,-8$ & 4.3 \\
Left fusiform gyrus (BA 18) &
\end{tabular}

\footnotetext{
${ }^{a}$ Talairach and Tournoux, 1988.
} 


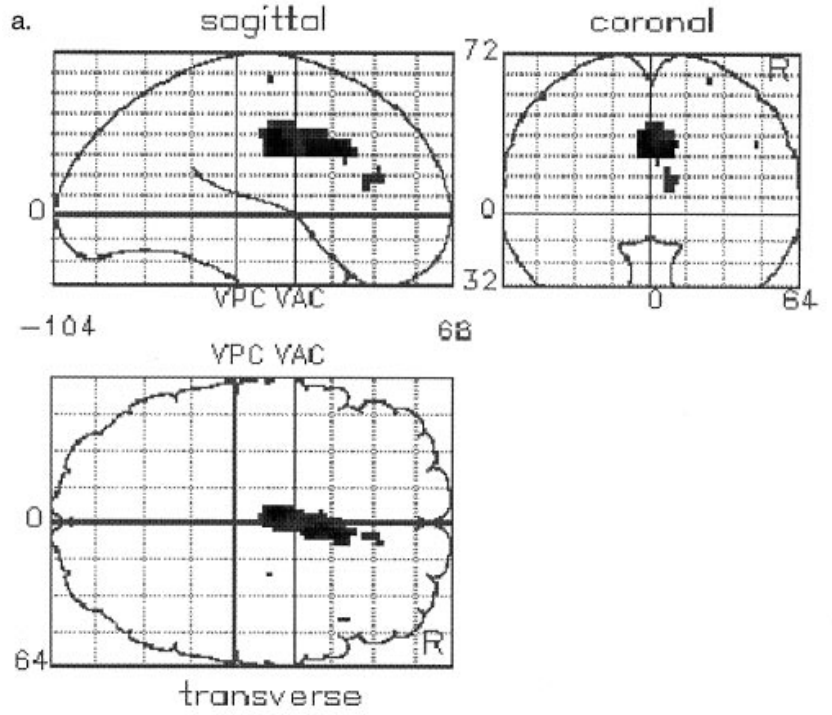

b.

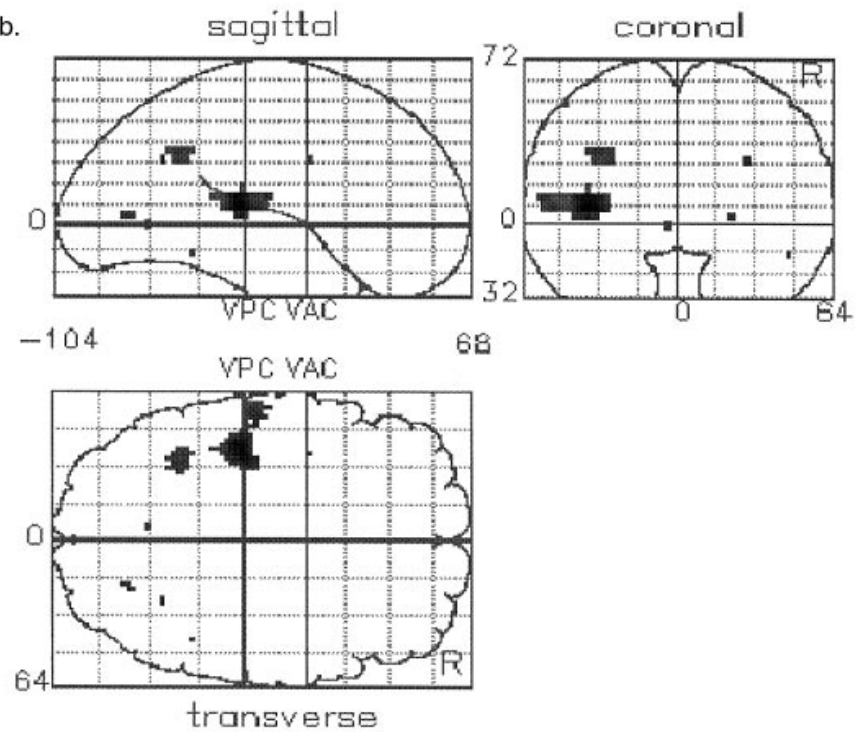

Figure 3. SPMs presented as in Figure 2. $a$, Brain regions in which there is a significant failure of activation in association with performance of the verbal fluency task. The single area seen is the anterior cingulate gyrus. $b$, Brain regions in which there is a significant failure of deactivation in association with performance of the verbal fluency task. The main area seen is the superior temporal gyrus. There is also a smaller area of significant difference above it in the inferior parietal lobe.

late gyrus, the right middle frontal gyrus, and the left fusiform gyrus (Table 3).

\section{Group $\times$ task interactions}

Group differences in cognitive task-related activations and deactivations were determined in all nonapomorphine scans. The group comparison revealed two critical differences in the form of a relative failure of activation in schizophrenia in the anterior cingulate cortex and a relative failure of deactivation in schizophrenia in the left superior temporal gyrus and the left inferior parietal lobe (see Fig. 3b, Table 4). Although the focus of impaired cingulate activation is on the right, the spatial resolution of our technique does not allow a strong statement regarding laterality because of its close proximity to the midline. Additionally, at a reduced level of significance, the failure of activation extends to

\begin{tabular}{lll}
\hline Table 4. Group $\times$ task interactions & & \\
& $\begin{array}{l}\text { Coordinates } \\
(x, y, z)\end{array}$ & $\begin{array}{l}Z \\
\text { score }\end{array}$ \\
Region & & \\
\hline Relative failures of activation in schizophrenia & & \\
$\quad$ Anterior cingulate gyrus (BA 24/32) & $-4,-6,32$ & 4.7 \\
& $6,16,28$ & 4.4 \\
& $6,6,28$ & 4.2 \\
Relative failures of deactivation in schizophrenia & $8,32,16$ & 3.3 \\
Left superior temporal gyrus & $-38,-28,8$ & 4.8 \\
$\quad$ (BA 22/40) & $-52,-24,8$ & 3.7 \\
& $-56,-18,12$ & 3.7 \\
Left inferior parietal lobe (BA 39/40) & $-32,-56,32$ & 3.6 \\
\hline
\end{tabular}

${ }^{a}$ Talairach and Tournoux, 1988.

the left. The terms "activation" and "deactivation" are used here in the functional neuroimaging sense and are not equivalent to excitation and inhibition in the neurophysiological sense.

\section{Apomorphine/cognitive-task interactions}

In this analysis, the functional effects of apomorphine are most appropriately framed in the context of its modulatory influences, i.e., effects on a task-induced activation. The critical question is whether there were task-induced activations that were modulated (either attenuated or augmented) by apomorphine. Therefore, the patterns of predrug activations and deactivations were compared to those occurring postdrug both within and between groups. Pre- and postplacebo scans were included in the analysis, as above, to remove order effects (i.e., we looked for a three-way interaction relative to placebo). There were no significant modulations of task-related activity in the control subjects. In the schizophrenic group, an apomorphine augmentation of the verbal fluency activation was observed in the anterior cingulate cortex and, at a lower threshold, in the prefrontal cortex bilaterally (see Table 5).

A between-group comparison of the apomorphine-related augmentations was constrained to the subset of voxels identified by the analysis differential verbal fluency activations between the two groups. This preselection represents a test of two independent hypotheses: (1) the area is differentially activated in schizophrenia; and (2) this activation is modulated by apomorphine. The procedure combines the outcome of two orthogonal sets of contrasts to yield a SPM in which the statistical significance represents the joint probability of a type I error for the two sets of contrasts. In the present case, the contrasts were each thresholded at $p<0.01$ and regions containing voxels in which apomorphine-related augmentations (schizophrenic vs controls) occurred at conjoint significance level of $p<0.0001$ (uncorrected) were considered to be reliable. This comparison showed that there is an augmentation in the task-related anterior cingulate activation that is significantly greater in schizophrenic subjects (see Table 5, Fig. 4).

Finally, there was an attenuation of task-related activity in the left superior/middle temporal gyrus in the schizophrenic group; postapomorphine, which failed to reach significance at our predetermined threshold, was significant at $p<0.015$ (uncorrected). This finding is presented in Figure 5.

\section{DISCUSSION}

Functional imaging-based approaches to schizophrenia have primarily emphasized segregated or regional brain dysfunction 


\begin{tabular}{lc}
\hline Table 5. & $\begin{array}{c}\text { Coordinates } \\
(x, y, z)\end{array}$ \\
Region & $10,20,32$ \\
\hline Increases in cognitive task-related activity produced by apomorphine (schizophrenic subjects) & $Z$ score \\
$\quad$ Anterior cingulate cortex (BA 24/32) & $42,26,32$ \\
Right medial frontal gyrus (BA 9) & $-32,14,20$ \\
Left inferior frontal gyrus (BA 45) & 4.3 \\
Increases in cognitive task-related activity produced by apomorphine that significantly differ & 3.7 \\
$\quad$ between schizophrenic and control subjects & $-4,-10,28$ \\
Anterior cingulate cortex (BA 24/32) & $8,18,28$ \\
\end{tabular}

a Talairach and Tournoux, 1988.

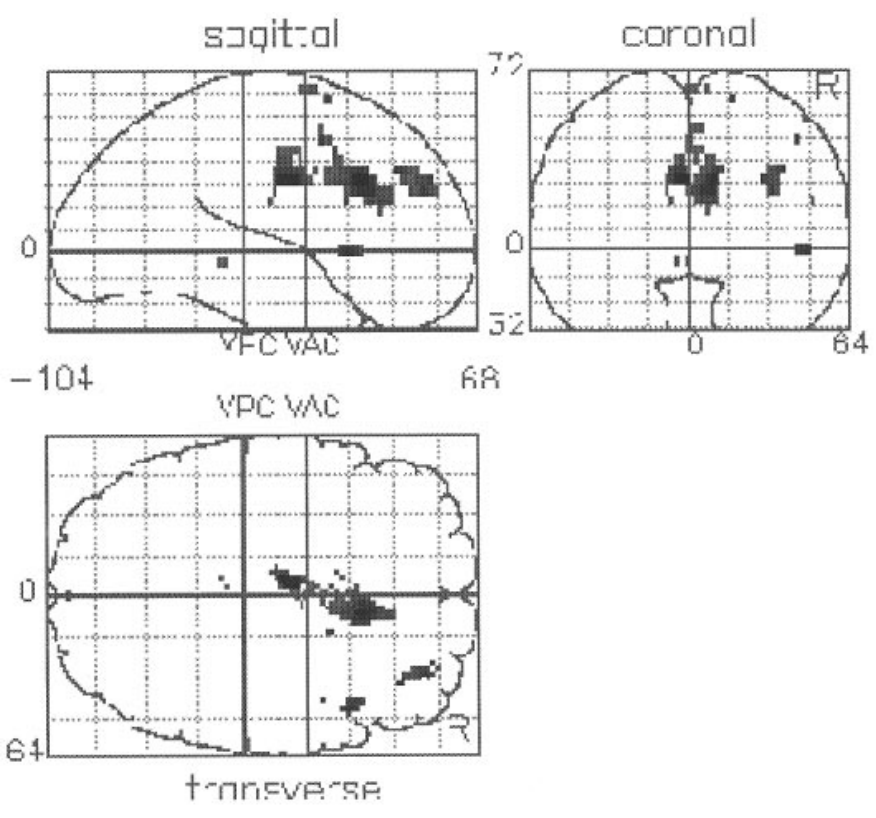

Figure 4. SPM presented as in Figures 2 and 3. This shows areas of significant ( $p<0.005$ conjoint significance) difference in drug-task interaction between the schizophrenic group and the control group. The area in which there was an augmenting effect of the drug on the task related activity occurring in schizophrenics compared to controls is shown to be the anterior cingulate gyrus.

(Chua and McKenna, 1995). There is evidence that regional dysfunctions, such as hypofrontality and impaired frontal activation (Berman et al., 1988; Weinberger et al., 1988), are not invariant findings, suggesting that they primarily reflect the current mental state rather than fundamental aspects of the disease process (Liddle et al., 1992; Dolan et al., 1993). Modification of task requirements can result in similar patterns of activation in schizophrenic patients and control subjects (Frith et al., 1995). An approach to the analysis of functional imaging data that emphasizes neural integration, based on measures of functional connectivity, has, furthermore, implicated a dysfunction of large-scale neuronal interactions, as evidenced by a disruption of frontotemporal interactions, in schizophrenia (Friston et al., 1994; Friston and Frith, 1995).

Our findings indicate both segregated and integrative dysfunction. A failure of cognitive task-related activation in the anterior cingulate cortex in the schizophrenic patients, and the modulation of this dysfunction by a dopaminergic perturbation, suggested a segregated abnormality. The absence of the normal reciprocal interaction between the prefrontal and the superior temporal cortex in schizophrenia, i.e., failure of task-related deactivation of the superior temporal gyrus in the schizophrenic group, can be interpreted within the context of impaired functional integration.

\section{Comparison of verbal fluency task-related activity across groups}

Control subjects showed activations in anterior cingulate and dorsolateral prefrontal cortex bilaterally with reciprocal deactivations in superior temporal and posterior cingulate cortex. Under the verbal fluency condition, schizophrenic patients showed a qualitatively similar pattern, as has been reported in chronic schizophrenic subjects using the same tasks (Frith et al., 1995). A formal comparison of the groups indicated a significant failure of activation of the anterior cingulate cortex in schizophrenic patients (Fig. 3a). This failure supports other functional imaging evidence of an anterior cingulate abnormality in schizophrenia (Andreasen et al., 1992; Liddle et al., 1992; Tamminga et al., 1992; Berman et al., 1995). Frith et al. (1995), using an identical paradigm to the present study, failed to find a difference in anterior cingulate activation between control and chronic schizophrenic subjects. However, the latter patients were all receiving regular doses of dopamine-blocking medication, which suggests that taskrelated cingulate activation in schizophrenia is dependent on the functional state of dopamine inputs (see below).

Activation of the anterior cingulate is a common finding in PET studies (Frith et al., 1991a,b; Fletcher et al., 1995) engaging selective attention to a stimulus or task and the inhibition of inappropriate, competing responses. Lesions to this region are also associated with a wide range of neuropsychological disorders including aberrant social behavior, akinetic mutism, diminished self-awareness, and depression (Devinsky et al., 1995). Its widespread connections and functional heterogeneity (Devinsky et al., 1995) suggest a role in the regulation or coordination of activity within interconnected brain areas. For example, one study showed that simultaneous performance of a distracting motor and memory task led to an increase in cingulate activation and a concurrent decrease in left prefrontal activation (Fletcher et al., 1995). One possibility is that an abnormality here leads to dysregulation of its modulatory functions in the control of task-related corticocortical interactions.

The finding of "normal" prefrontal activation is at variance with some previous PET studies in schizophrenia (Weinberger et al., 1986, 1988; Berman et al., 1995). It is in agreement, however, with a study in which performance was optimized by pacing the task (Frith et al., 1995). Although the issue of prefrontal function in 
Figure 5. Graphic representation of the trend toward an augmentation of superior/middle temporal lobe deactivations produced by apomorphine. Equivalent blood flow values have been averaged from a voxel in the left superior/middle temporal lobe and are shown pre- and postapomorphine as labeled. As shown, in the control group there is a preapomorphine task-related deactivation that is hardly changed after administration of the drug. In the schizophrenic group, there is, in this area, an initial activation that becomes a deactivation after drug administration.
Relative activations in Left Superior Temporal Gyrus $(\mathrm{ml} / \mathrm{dl} / \mathrm{min})$

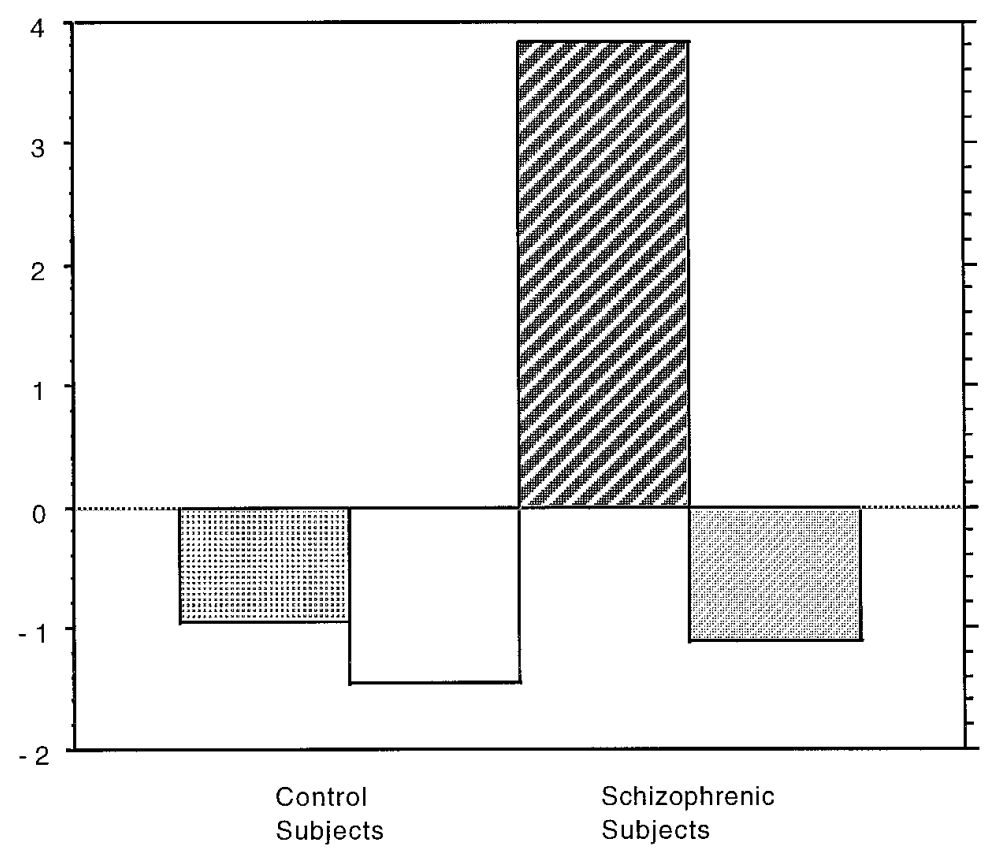

Control subjects - pre-apomorphine
$\square$ Control subjects - post-apomorphine
$\mathbb{Z}$ Schizophrenic subjects - pre-apomorphine
$\mathbb{E}$ Schizophrenic subjects - post-apomorphine schizophrenia has yet to be resolved, there is increasing evidence for a core pathology in the anterior cingulate cortex. Postmortem studies have shown a loss of interneurons, with changes maximal in layer II, a selective glutamatergic neuron loss, and altered $\mathrm{GABA}_{\mathrm{A}}$ binding. It has been suggested, furthermore, that a loss of the inhibitory interneurons in layer II results in increased dopaminergic inputs to GABAergic neurons (Benes et al., 1986, 1987, 1991, 1992). Although the failure of anterior cingulate activation is highlighted in the present study, the absence of a prefrontal abnormality must be seen in the context of data indicating abnormalities in prefrontal cortex structure (Selemon et al., 1995) and function (Berman et al., 1986; Weinberger et al., 1986) in schizophrenia. Our findings must be interpreted in the context of the specific cognitive challenge used.

\section{Dopamine and cortical function in schizophrenia}

Our experimental design allowed investigation of in vivo dopaminergic effects on task-related neuronal activity. Apomorphine is a nonselective dopamine agonist that has been used extensively as a probe of dopaminergic function in both schizophrenic and depressed patient populations (Meltzer et al., 1984). At low dosage, its predominant effects are presynaptic, resulting in a net reduction of dopaminergic neurotransmission (Skirboll et al., 1979).

In the present study, there was no significant effect on taskrelated changes in the comparison of apomorphine-treated with placebo-treated control subjects. The absence of an apomorphine effect on this activation can be reconciled with evidence that dopaminergic modulation of prefrontal function is highly tuned (Goldman-Rakic et al., 1992). One interpretation, therefore, is that the perturbation of cortical dopamine input in controls was insufficient to lead to an effect on regional physiology. We have shown previously a regulatory effect of this dose (and a lower dose) of apomorphine on prefrontal-mediated memory function (Grasby et al., 1992b), a finding that, coupled with the present finding, suggests that dopaminergic regulation of prefrontal function is highly specific and strongly task-dependent. For example, if the current task engaged prefrontal cortex to a lesser degree than in the previous study using a different paradigm (Grasby et al., $1992 b$ ), then it may be less likely that a drug-induced modulation of prefrontal activity would be seen.

When examined independently, the schizophrenic subjects, unlike control subjects, revealed a significant effect of apomorphine on task-related changes in $\mathrm{rCBF}$ in the anterior cingulate cortex. This effect, an augmentation of activation, retained significance when a direct comparison was made between the schizophrenic and the control subjects in the same area where the schizophrenic patients showed an abnormality in cognitive task-related activation. This finding (Fig. 4) indicates that the anterior cingulate cortex functions abnormally in the context of the verbal fluency task and that this area is hyper-responsive to a dopaminergic perturbation. One interpretation of this finding is that schizophrenia is associated with a hyperdopaminergic state that exerts a net inhibitory effect on task related activations. There is a broad range of literature indicating the detrimental effects of dopamine on cognitive function at the behavioral (Murphy et al., 1996) and single cell (Williams and Goldman-Rakic, 1995) levels. Apomorphine, at the low dose used in the present study, has a predominantly presynaptic effect, resulting in a functional decrease in dopamine neurotransmission (Brozoski et al., 1979), which could account for the postdrug increase in task-related activity. Our previous study of schizophrenic subjects receiving dopamine an- 
tagonists found normal anterior cingulate activation in the context of an identical verbal fluency task (Frith et al., 1995), consistent with the suggestion that dopamine blockade can normalize cingulate function. It is noteworthy that apomorphine at a very similar dosage has been shown to produce acute amelioration of schizophrenic symptoms (Tamminga, 1978).

\section{Task-related changes in the temporal cortex}

Previous PET studies in normal volunteers have shown relative deactivations in the lateral temporal regions bilaterally in association with a variety of cognitive tasks that activate the prefrontal cortex (Frith et al., 1991a; Grasby et al., 1993; Fletcher et al., 1995). This finding was seen again in the control group under the verbal fluency condition. The schizophrenic subjects showed a significant failure of this deactivation (Fig. 3). Thus, there was a disruption of normal task-related reciprocal pattern of activations and deactivations in the schizophrenic patients. Such deactivations have been conceptualized as reflecting a complex phenomenon involving the integration of internally generated words or actions into the perceptual domain (Frith, 1992; Friston and Frith, 1995). The finding of a failure of left temporal deactivation in the schizophrenic group has been shown previously in three groups of schizophrenic subjects (independent of their ability to perform the task) (Frith et al., 1995), and it was suggested that it reflected an abnormality of functional connectivity between prefrontal and temporal structures (Friston et al., 1994). A disruption of functional connectivity between the prefrontal and temporal cortex may reflect a core pathophysiology in schizophrenia involving a lack of integration across large scale neuronal networks. The current study, in an unmedicated sample of patients, indicates that this finding is not explicable on the basis of the effects of antipsychotic medication.

Although not reaching our criterion for statistical significance, the observation that apomorphine produces an augmentation of the task-related temporal deactivation in the schizophrenic patients is interesting. Whether it reflects a direct effect of the apomorphine on the temporal lobe or a "downstream" effect of the anterior cingulate change (i.e., a normalization of task-related cingulate activation influences the fronto-temporal interactions resulting in a normalization of task-related deactivation) is unclear. Although highly speculative and bearing in mind the fact that it is shown only as a trend in our data, there is some evidence from nonhuman primate work that the anterior cingulate cortex can modulate activity in other brain regions, notably the temporal lobes (Muller-Preuss et al., 1980). However, the previous study (on chronic, medicated patients) showed abnormal temporal deactivation in the face of apparently normal cingulate activity (Frith et al., 1995), so this interpretation is tentative.

In summary, we have demonstrated a functional abnormality in the anterior cingulate cortex in schizophrenic subjects. Further, dopaminergic perturbation results in an augmentation of task-related activation in this region and a trend toward a normalization of deactivation in the temporal lobe. Although the data must be treated as preliminary, they do suggest that schizophrenia may be associated with both segregated (anterior cingulate) and integrated (frontotemporal) abnormalities. Furthermore, our observation that apomorphine-related reversal of the segregated abnormality is associated with a trend toward normalization of impaired temporal deactivation fuels our speculation that the abnormality of brain integration in schizophrenia may be caused by a segregated dysfunction in the anterior cingulate region, the functions of which involve modulation of cortico-cortical interactions.

\section{REFERENCES}

American Psychiatry Association (1987) Diagnostic and statistical manual of mental disorders DSM-III-R, 3rd Ed. Washington, DC: American Psychiatry Association.

Andreasen NC, Rezai K, Alliger R, Swayze VW, Flaum M, Kirchner P, Cohen G, O'Leary DS (1992) Hypofrontality in neuroleptic-naive patients and in patients with chronic schizophrenia: assessment with xenon 133 single-photon emission computed tomography and the Tower of London. Arch Gen Psychiatry 49:943-958.

Benes FM, Davidson J, Bird JE (1986) Quantitative cytoarchitectural studies of schizophrenic cortex. Arch Gen Psychiatry 43:31-35.

Benes FM, Majocha R, Bird ED, Marotta CA (1987) Increased vertical axon numbers in cingulate cortex of schizophrenics. Arch Gen Psychiatry 44:1017-1021.

Benes FM, McSparren J, Bird ED, SanGiovanni JP, Vincent SI (1991) Deficits in small interneurons in prefrontal and cingulate cortex of schizophrenic and schizoaffective patients. Arch Gen Psychiatry 48:996-1001.

Benes FM, Vincent SI, Alsterberg G, Bird ED, SanGiovanni JP (1992) Increased $\mathrm{GABA}_{\mathrm{A}}$ receptor binding in superficial layers of schizophrenic cingulate cortex. J Neurosci 12:924-929.

Berman KF, Zec RF, Weinberger DR (1986) Physiologic dysfunction of dorsolateral prefrontal cortex in schizophrenia. Arch Gen Psychiatry 43:126-135.

Berman KF, Illowsky BP, Weinberger DR (1988) Physiological dysfunction of dorsolateral prefrontal cortex in schizophrenia. IV. Further evidence for regional and behavioral specificity. Arch Gen Psychiatry 45:616-622.

Berman KF, Gold JM, Noga JT, Abi-Dargham A, Van Horn JD, Weinberger DR (1995) A PET study of working memory in schizophrenia: effects of performance level. Soc Neurosci Abstr 21:110.6.

Bleuler E (1987) Dementia praecox or the group of schizophrenias. In: The clinical routes of the schizophrenia concept (Cutting J, Shepherd M, eds). Cambridge: Cambridge UP.

Brozoski TJ, Brown RM, Rosvold HE, Goldman PS (1979) Cognitive deficit caused by regional depletion of dopamine in prefrontal cortex of rhesus monkey. Science 205:929-932.

Chua SE, McKenna PJ (1995) Schizophrenia, a brain disease? A critical review of structural and functional review of cerebral abnormality in the disorder. Br J Psychiatry 166:563-582.

Creese I, Burt DR, Snyder SH (1976) Dopamine receptor binding predicts clinical and pharmacological potencies of antischizophrenic drugs. Science 192:481-483.

Davidson M, Keefe RSE, Mohs RC, Siever LJ, Losonczy MF, Horvath TB, Davis KL (1987) L-Dopa challenge and relapse in schizophrenia. Am J Psychiatry 141:934-938.

Devinsky O, Morrell MJ, Vogt BA (1995) Contributions of anterior cingulate cortex to behaviour. Brain 118:279-306.

Dolan RJ, Bench CJ, Liddle PF, Friston KJ, Frith CD, Grasby PM, Frackowiak RSJ (1993) Dorsolateral prefrontal cortex dysfunction in the major psychoses: symptom or disease specificity. J Neurol Neurosurg Psychiatry 56:1292-1298.

Dolan RJ, Fletcher P, Frith CD, Friston KJ, Frackowiak RSJ, Grasby PJ (1995) Dopaminergic modulation of an impaired cognitive activation in the anterior cingulate cortex in schizophrenia. Nature 378:180-183.

Engel AK, Konig P, Kreiter AK, Schillen TB, Singer W (1992) Temporal coding in the visual cortex: new vistas on integration in the nervous system. Trends Neurosci 15:218-226.

Farde L, Sedvall G, Wiesel FA, Hall H, Halldin C, Stone-Elander S (1988) Brain dopamine receptors in schizophrenia: PET problems. Arch Gen Psychiatry 45:599-600.

Farde L, Wiesel FA, Stone-Elander S, Halldin C, Nordstrom A-L, Hall H, Sedvall G (1990) D2 dopamine receptors in neuroleptic-naive schizophrenic patients. Arch Gen Psychiatry 47:213-219.

Fletcher PC, Frith CD, Grasby PM, Shallice T, Frackowiak RSJ, Dolan RJ (1995) Brain systems for encoding and retrieval of auditory-verbal memory: an in vivo study in humans. Brain 118:401-416.

Friston KJ, Frith CD (1995) Schizophrenia: a disconnection syndrome? Clin Neurosci 3:89-97.

Friston KJ, Grasby P, Frith CD (1991) The neurotransmitter basis of cognition: psychopharmacological activation studies using positron emission tomography. In: Exploring brain functional anatomy with positron tomography, pp 76-92. Chichester: Wiley. 
Friston KJ, Frith CD, Fletcher P (1994) Abnormal fronto-temporal interactions in schizophrenia. In: Biology of schizophrenia and affective disorders (Watson SJ, ed). New York: Raven.

Friston KJ, Holmes AP, Worsley KJ, Poline JB, Frith CD, Frackowiak RSJ (1995) Statistical parametric maps in functional imaging: a general approach. Hum Brain Mapp 2:189-210.

Friston KJ, Ashburner J, Poline J-B, Frith CD, Heather JD, Frackowiak RSJ (1995) Spatial realignment and normalisation of images. Hum Brain Mapp 2:165-189.

Frith CD (1992) The cognitive neuropsychology of schizophrenia. Hove: Lawrence Erlbaum.

Frith CD, Friston KJ, Liddle PF, Frackowiak RSJ (1991a) Willed action and the prefrontal cortex in man: a study with PET. Proc R Soc Lond [Biol] 244:241-246.

Frith CD, Friston KJ, Liddle PF, Frackowiak RSJ (1991b) A PET study of word finding. Neuropsychologia 29:1137-1148.

Frith CD, Friston KJ, Herold S, Silbersweig D, Fletcher P, Cahill C, Dolan RJ, Frackowiak RSJ, Liddle PF (1995) Regional brain activity in chronic schizophrenic patients during the performance of a verbal fluency task. Br J Psychiatry 167:343-349.

Goldman-Rakic PS, Lidow MS, Smiley JF, Williams MS (1992) The anatomy of dopamine in monkey and human prefrontal cortex. J Neural Transm [Suppl] 36:163-177.

Grasby P, Friston K, Bench CJ, Frith C, Cowen P, Liddle P, Frackowiak RSJ, Dolan RJ (1992a) The effect of apomorphine on regional cerebral blood flow in normal volunteers. Schiz Res 6:149.

Grasby PM, Friston KJ, Bench CJ, Frith CD, Paulesu E, Cowen PJ, Liddle PF, Frackowiak RSJ, Dolan RJ (1992b) The effect of apomorphine and buspirone on regional cerebral blood flow during the performance of a cognitive task: measuring neuromodulatory effects of psychotropic drugs in man. Eur J Neurosci 4:1203-1212.

Grasby PM, Frith CD, Friston KJ, Bench C, Frackowiak RSJ, Dolan RJ (1993) Functional mapping of brain areas implicated in auditory memory function. Brain 116:1-20.

Hietala J, Syvälahti E, Vuorio K, Räkköläinen V, Bergman J, Haaparanta M, Solin O, Kuoppamäki M, Kirvelä O, Ruotsalainen U, Salokangas RKR (1995) Presynaptic dopamine function in striatum of neuroleptic-naive schizophrenic patients. Lancet 346:1130-1131.

Johnstone EC, Crow TJ, Frith CD, Carney MWP, Price JS (1978) Mechanism of the antipsychotic effects in the treatment of acute schizophrenia. Lancet 1:848-851.

Liddle P, Friston KJ, Frith CD, Hirsch SR, Jones T, Frackowiak RSJ (1992) Patterns of cerebral blood flow in schizophrenia. Br J Psychiatry 160:179-186.

Meltzer HY, Kolakowska T, Fang VS, Fogg L, Robertson A, Lewine R, Strahilevitz M, Busch D (1984) Growth hormone and prolactin response to apomorphine in schizophrenia and the major affective disorders: relation to duration of illness and depressive symptoms. Arch Gen Psychiatry 41:512-519.

Muller-Preuss P, Newman JD, Jurgens U (1980) Evidence for an anatomical and physiological relationship between "cingular" vocalisation area and the auditory cortex in the squirrel monkey. Brain Res 202:307-315.
Murphy BL, Arnsten AFT, Goldman-Rakic PS, Roth RH (1996) Increased dopamine turnover in the prefrontal cortex impairs spatial working memory performance in rats and monkeys. Proc Natl Acad Sci USA 93:1325-1329.

Phillips CG, Zeki S, Barlow HB (1984) Localisation of function in the cerebral cortex: past, present and future. Brain 107:327-361.

Randrup A, Munkvad I (1972) Evidence indicating an association between schizophrenia and dopaminergic hyperactivity in the brain. Orthomol Psych 1:2-7.

Reith J, Benkelfat C, Sherwin A (1994) Elevated dopa decarboxylase activity in living brain of patients with psychosis. Proc Natl Acad Sci USA 91:11651-11654.

Seeman P, Lee T, Chau-Wong M, Wong K (1976) Antipsychotic drug doses and neuroleptic/dopamine receptors. Nature 261:717-719.

Selemon LD, Rajkowska G, Goldman-Rakic PS (1995) Abnormally high neuronal density in the schizophrenic cortex: a morphometric analysis of prefrontal area 9 and occipital area 17. Arch Gen Psychiatry 52:805-818.

Skirboll LR, Grace AA, Bunney BS (1979) Dopamine auto- and postsynaptic receptors: electrophysiological evidence for differential sensitivity to dopamine agonists. Science 206:80-82.

Talairach J, Tournoux P (1988) Co-planar stereotaxic atlas of the human brain, pp 1-122. Stuttgart: George Thieme Verlag.

Tamminga CA (1978) Schizophrenic symptoms improve with apomorphine. Science 200:567-568.

Tamminga CA, Thaker GK, Buchanan R, Kirkpatrick B, Alphs LD, Chase TN, Carpenter Jr WT (1992) Limbic system abnormalities identified in schizophrenia using positron emission tomography with flurodeoxyglucose and neocortical alterations with deficit syndrome. Arch Gen Psychiatry 49:522-530.

Tononi G, Sporns O, Edelman GM (1992) Reentry and the problem of integrating multiple cortical areas: simulation of dynamic integration in the visual system. Cereb Cortex 2:310-335.

Tononi G, Sporns O, Edelman GM (1994) A measure for brain complexity: relating functional segregation and integration in the nervous system. Proc Natl Acad Sci USA 91:5033-5037.

Weinberger DR, Berman KF, Zec RF (1986) Physiologic dysfunction of dorsolateral prefrontal cortex in schizophrenia. I. Regional cerebral blood flow evidence. Arch Gen Psychiatry 43:114-124.

Weinberger DR, Berman KF, Illowsky BP (1988) Physiological dysfunction of dorsolateral prefrontal cortex in schizophrenia. III. A new cohort and evidence for a monoaminergic mechanism. Arch Gen Psychiatry 45:609-615.

Wernicke C (1906) Grundrisse der psychiatrie. Thieme: Leipzig.

Williams GV, Goldman-Rakic PS (1995) Modulation of memory fields by dopamine D1 receptors in prefrontal cortex. Nature 376:572-575.

Wong DF, Wagner Jr HN, Tune LE, Dannals RF, Pearlson GD, Links JM, Tamminga CA, Broussolle EP, Ravert HT, Wilson AA, Toung JKT, Malat J, Williams JA, O’Tuama LA, Snyder SH, Kuhar MJ, Gjedde A (1986) Positron emission tomography reveals elevated D2 dopamine receptors in drug-naive schizophrenics. Science 234:1558-1563. 